\title{
Differences of craniotype distribution and types of face among apparently healthy men from different regions of Ukraine
}

\author{
I.V. Gunas ${ }^{1}$, M.M. Shinkaruk-Dykovytska², O.O. Kotsyura², V.O. Orlovskiy², \\ S.V. Dmytrenko², A.V. Shayuk ${ }^{3}$, A.A. Glushak ${ }^{2}$ \\ ${ }^{1}$ Intertional Academy of Integrative Anthropology, Vinnitsa, Ukraine \\ ${ }^{2}$ Vinnitsa National Medical University named after M.I. Pirogov, Vinnitsa, Ukraine \\ ${ }^{3}$ Zhytomyr State University named after Ivan Franko, Zhytomyr, Ukraine
}

[Received: 21 December 2016; Accepted: 9 February 2017]

\begin{abstract}
Established peculiarities of craniotype distribution and types of face in somatically healthy men depend on regional affiliation. In all regions of Ukraine, markedly greater brachycephaly percentage was found, indicating the trend towards brachycephalisation and prevalence of men with narrow and very narrow face, which confirms gracilisation. The study showed a small number of regional differences in the distribution of specific types of the skull and face, indicating that the population of Ukraine is very homogeneous in anthropological composition and none of the presented Ukrainian regional types is beyond anthropological type, common to people in general. (Folia Morphologica 2017; 76, 3: 473-477)
\end{abstract}

Key words: cephalometry, practically healthy men, craniotype, type of face, regional differences

\section{INTRODUCTION}

Epochal morphological reorganisation processes of various dimensions of the human body (head- and brahy-dolichocephaly, postcranial skeleton - secular trend, gracilisation and so on) can be traced from the beginning of widespread colonisation of the planet by modern representatives of Homo Sapiens [9]. On cranium this process manifested in change of its degree of circularity, i.e. in form change but stability of its absolute size. Postcranial skeleton, by contrast, in relative stability of proportions respond by periodic changes of total body size. In the foreseeable historical period in some regions took place a periodic change in the shape of the skull (processes of brahy- and dolichocephaly) and face. Similar changes in body proportions have not been observed, despite the fact that the absolute body size has changed quite often. This indicates a much more conservative system of postcranial skeleton (a much deeper "genetic memory" which it is carrying). In addition, the appearance of facial and cranial parts of the skull is quite recent in the timeline of evolutionary events $[14,16]$.

After comparing the value of head circumference in 2-year-old children in 26 countries that participated in drafting the World Health Organisation growth standards, Natale and Radzhahopalan [14] found significantly greater variability of this trait among different ethnic groups compared to height and weight. Importantly, the head size is determined by the innate differences in the anatomy of the skull and there are significant morphological differences between, for example, Europeoid and Mongoloid skulls.

Address for correspondence: Dr. Igor Gunas, Doctor of Medical Sciences, Prof., Executive Director of the International Academy of Integrative Anthropology, Vinnitsa, Ukraine, tel: 073-0376746, e-mail: igor.gunas@mail.ru 
Therefore, to study the variability of skull morphology and compare it in the representatives of different ethnic groups, cephalometric data should be optimally used. Cephalometric indices are a kind of "labels" that allow us to obtain information about age, gender of a human, race, ethnicity and the impact of migration on racial-ethnic composition of the population of certain areas [3].

In the global anthropological literature, attempts can be found to perform total cephalometry data analysis for all modern human races. Researchers have studied a number of cranial series, established and refined values of a number of diagnostic features, assessed living individuals, studied the cranial and facial parts of the skull of the Japanese, Koreans, Russians, Buryats, Khakassians, Tuvans, Belarusians, Mexicans, Croats, Serbs, Bulgarians, Austrians, Czechs, Poles and others $[2,4,5,9-13,17,19,21,22]$.

This allows, on the one hand, providing an information base for comparative anatomical and anthropological studies of different ethnic groups and identifying their similar and different morphological features and, on the other, to create a biometric basis for multivariate analysis of the relationships between the different anatomical structures of the facial and cranial skull $[8,14]$.

Perhaps the success of such research would be more fruitful if ethnic differences in size of cranial and facial skull were supported by data concerning their distribution on craniotype and types of face in certain populations and subpopulations. In addition, specific cephalometric norm should be determined for each ethnic group based on the study of healthy members of the population $[1,14,21]$.

The purpose of this study is to identify the distribution of craniotypes and types of face in somatically healthy Ukrainian men, depending on regional affiliation.

\section{MATERIALS AND METHODS}

From the population of the previous survey (using a screening questionnaire [6], including more than 3,500 men aged from 19 to 35 years from different regions of Ukraine) the authors selected 200 healthy men, the third-generation residents of different ethnic territorial regions, with satisfactory environmental conditions for the population, in whom they conducted a cephalometric study. The Bioethics Committee of the Vinnitsa National Medical University named after N.I. Pirogov (protocol No. 8 from 09.10.2013) found that con- ducted research fully corresponded to ethical, moral and legal requirements according to the order Ministry of Health (MOH) of Ukraine from 01.11.2000 No. 281 and was consisted with major bioethical standards of the Helsinki Declaration, the European Convention on human rights and biomedicine (1977).

Cephalometric study consisted in determining the parameters of cranial and facial parts of the head by using large sliding calliper with full-scale system of Martin and soft measuring tape. Cephalometric study was conducted with regard to accepted guidelines and anatomical points [18].

Head shape was defined by the formula: maximum width of the head (occipital diameter) $\times 100 /$ / maximum length of the head (the distance from the glabella to the opisthocranion) [23], with the value of 75.9 attributed to dolichocephalic; 76.0-80.9to mesocephalic; 81.0-85.4 - to brachiocephalic; 85.5 or more - to hyperbrachiocephalic type.

The value of facial index (morphological index of Garson) obtained by the formula: morphological length of the face $\times 100 /$ maximum width of the face [15], with the value of the index up to 78.9 classified as a very broad face; $79.0-83.9$ - broad face; 84.0-87.9 - the average face; 88.0-92.9 - narrow face; 93.0 or more - very narrow face.

Statistical analysis of the results was performed using the statistical licensed software package Statistica 6.1. Reliability of differences between independent quantitative values was determined using formula by Weber [20].

\section{RESULTS}

We have found that in the northern region of Ukraine $(n=32)$ the percentage of men with dolichocephaly $(6.3 \%)$ was significantly $(p<0.01)$ lower compared to the percentage of those with meso(34.4\%) and brachiocephaly (37.5\%).

In men of the south region of Ukraine $(n=33)$ dolichocephaly $(6.1 \%)$ was significantly $(p<0.05-$ -0.001 ) less frequent compared to the percentages of meso- $(30.3 \%)$ and brachiocephaly $(45.5 \%)$ and the percentage of men with hyperbrachiocephaly (18.2\%) was significantly $(p<0.05)$ lower compared to the percentage of men with brachiocephaly.

In men of the central region of Ukraine $(n=64)$ the percentage of men with brachiocephaly (39.1\%) was significantly $(p<0.05-0.01)$ higher compared to percentages of doliho- (17.2\%) and hyperbrachiocephaly $(18.8 \%)$. 
In men of the western region of Ukraine $(n=36)$ the prevalences of brachiocephaly $(50.0 \%)$ and hyperbrachiocephaly (30.56\%) were significantly $(p<0.05-0.001)$ higher compared to the prevalences of doliho- (8.3\%) and mesocephaly (11.1\%).

In men of the eastern region of Ukraine $(n=35)$ the prevalence of hyperbrachiocephaly (14.3\%) was significantly $(p<0.05)$ lower compared to the prevalence of brachiocephaly (40.0\%).

We have found that in men of the northern region of Ukraine $(n=32)$ the percentages of individuals with narrow (25.0\%) and very narrow face $(56.3 \%)$ were significantly $(p<0.05-0.001)$ higher compared to the percentages of men with very broad $(3.1 \%)$, wide $(6.25 \%)$ and average $(9.4 \%)$ face. The percentage of men with a very narrow face $(56.3 \%)$ was significantly $(p<0.05)$ higher compared to the percentage of men with narrow face (25.0\%).

In men of southern region of Ukraine $(n=33)$ the percentages of men with very narrow $(30.3 \%)$ and narrow face $(36.4 \%)$ were significantly $(p<0.05-$ -0.01 ) higher compared with the percentages of men with very broad $(3.0 \%)$, wide $(6.1 \%)$ and average (24.4\%) face.

In men of the central region of Ukraine $(n=64)$ the percentages of individuals with very wide $(1.6 \%)$ and wide $(10.9 \%)$ face were significantly $(p<0.05-0.01)$ lower compared with the percentages of men with very narrow $(45.3 \%)$, narrow $(28.3 \%)$ and average $(14.1 \%)$ face. The percentage of men with very narrow face $(45.3 \%)$ was significantly $(p<0.05)$ higher compared with the percentage of men with narrow $(28.3 \%)$ face.

In men of western region of Ukraine $(n=36)$ the percentage of individuals with very narrow face $(44.4 \%)$ was significantly $(p<0.05-0.001)$ higher compared with the percentages of men with very broad $(2.8 \%)$, wide $(5.6 \%)$ and narrow $(16.7 \%)$ face. The percentage of men with an average face $(30.6 \%)$ was significantly $(p<0.05)$ higher compared with the percentags of men with very broad $(2.8 \%)$ and broad face $(5.6 \%)$. The percentage of men with narrow face $(16.7 \%)$ was significantly $(p<0.05)$ higher compared with per cent of men with broad face $(2.8 \%)$.

In men of the eastern region Ukraine $(n=35)$ the percentage of individuals with very broad face $(0 \%)$ was significantly $(p<0.05-0.001)$ lower compared with the percentages of men with wide (11.4\%), medium (14.3\%), narrow (25.7\%) and very narrow $(48.6 \%)$ face. The percentage of men with very narrow face $(48.6 \%)$ was significantly $(p<0.05)$ higher compared with the percentages of men with wide $(11.4 \%)$, medium $(14.3 \%)$ and narrow $(25.7 \%)$ face.

\section{DISCUSSION}

Our studies found that in all regions of Ukraine a phenomenon of brachycephalisation can be observed.

According to Bunak [3], an important factor for epochal changes the morphology of the head was "a shift in dominant genes that directly or indirectly impact growth of two axes of brain box; in some combinations of sizes diameters lateral growth dominates, in others - longitudinal".

Over time, on all the territories inhabited by man occurred a process of shortening the skull. Skull continued to acquire more rounded, harmonious form. To explain this trend, a hypothesis was proposed about migration, which suggested that people were changing one by one. However, a more careful study revealed that the issue concerned a landmark brachycephalisation process in which the generations have shorter skull than their ancestors. In particular, one of the most striking tendencies of changing of the form of cranial skull is Slavic population in the East European Plain in the last millennium; there is a tendency to brachycephalisation, "rounding" of form of the skull due to a shortening of its longitudinal and expanding of its transverse diameter [1].

It has been established that in Japanese, Koreans and Mexicans over the past 100 years, brachycephalisation took place, along with a significant increase in body length [10-13]. However in many European populations opposite trend was observed - debrachycephalisation (dolichocephalisation) $[2,4,5,9,16,19$, 22]. Thus, the young generation of Croatia, Serbia, Austria tends to undergo dolichocephalisation due to significant reduction in the transverse diameter of the head and increase in the longitudinal diameter of head $[4,5,22]$. A process of debrachycephalisation has been evidenced by data of Russian, Czech, Bulgarian anthropologists and scientists of other countries $[2,9,16,19]$.

At the same time there are differences between closely related ethnic groups. Analysing tendencies of epochal transformation of the shape of the head in children and adolescents in Russia and Poland, Purundzhan and Khomyakov [17] believe that if the Russian population has already moved to a new stage of microevolutionary transformations, while the 
Polish population (data beginning of 1990s) was still at the preliminary stage.

Along with the phenomena of brachycephalisation and acceleration, over the past few centuries the population of Europe has become narrower in face. As a result, our study also found that all regions of Ukraine are dominated by individuals with narrow and very narrow face [8].

The length and width of the face and cranial index belong to the basic parameters for the classification of anthropological types. Despite the large internal unity of generalised anthropological types of ethnic Ukrainians in Eastern Europe, some variations can be still identified and are regionally localised. According to the data obtained during the Ukrainian anthropological expedition led by Dyachenko [7], it is known that on the mainland of Ukraine a pattern of strengthening from north to south the features of Europeoids - reduced brachiocephaly and lower relative width of the face. This trend has been found in Ukrainians of Moldova, Moldovans and Gagauz people and in parts of Europe located southwest of Ukrainian borders.

Throughout human history, the compositions of populations of various territories were different at different times. Change of anthropological indices and, in fact, an anthropological portrait, is continuous and is caused not only by migration, but occurs even when there is no mixing of diverse populations [1].

That's why our survey results contradict those obtained by Dyachenko [7] 50 years ago. In our study, we observed the weakening of brachiocephaly and reduction of the relative width of the face: the percentage of men with dolichocephaly in the eastern region $(22.9 \%)$ tended to be $(p=0.055$ and $p=$ $=0.067$ ) higher compared with the percentage of representatives of given craniotype of the north $(6.3 \%)$ and south regions $(6.1 \%)$; the percentage of men with a narrow face type in western region (16.7\%) had a tendency $(p=0.061)$ to be lower compared with the percentage of men with the same face type in southern region (36.4\%).

The percentages of individuals with a very narrow face indicated even opposite phenomenon described by the author: the percentage of men with very narrow type of face in southern region (30.3\%) was significantly $(p<0.05)$ lower compared with the percentage of men with the same type of face in the northern region (56.3\%).
It should be noted a small number of regional differences in the distribution of specific types of skull and face. Closest explanation for this situation is the anthropological hypothesis of the unity of the Slavs, which currently is the most reasonable and confirmed hypothesis of their origin. According to this hypothesis, all modern Slavic people are the descendants of the ancient people (ancient Slavs), who had a certain anthropological type inherent only to it [1].

We can conclude that the Ukrainian population of the East European Plain is quite homogeneous in anthropological structure, i.e. the difference between the different regions of Ukraine is insignificant and none of presented Ukrainian regional types exceeds the anthropological type common to people in general.

The uniqueness of this study consists in the fact that in Ukraine, whose area is $603,628 \mathrm{~km}^{2}$, located in four climatic and geographical environmental areas, is home for over 100 nationalities [1]. In this regard, the definition of the distribution of types of skull and face in different regions makes it possible to determine the anthropological composition of the territory and changes in the anatomical structure under various demographic factors of natural and socio-cultural nature $[1,9,17]$. Question of epochal variability size, shape of skull, distribution of craniotypes and types of face in healthy population living in Ukraine, gives reason to hypothesize about its microevolution character.

\section{CONCLUSIONS}

1. In apparently healthy men from different regions of Ukraine we have found a significantly higher percentage of men with brachiocephaly and narrow and very narrow face, indicating a reduction in microevolutionary processes in the study population.

2. In a studied sample of inhabitants of different regions of Ukraine there were only slight differences in percentage of subjects with specific types of skull and face, indicating homogeneity of anthropological structure of the population.

\section{REFERENCES}

1. Alekseeva TI. Anthropology and ethnic history. Eastern Slavs. M. Scientific World 2002: 342.

2. Brůzek J, Hajnis $K$, Tláskal $P$, et al. [Temporal trends and debrachycephalization in Czech children in the 1st year of life]. Cesk Pediatr. 1988; 43(4): 199-203, indexed in Pubmed: 3396104. 
3. Bunak VV. On the evolution of skull shape. Questions of anthropology. 1968; 30: 3-16.

4. Buretić-Tomljanović A, Ostojić S, Kapović M. Secular change of craniofacial measures in Croatian younger adults. Am J Hum Biol. 2006; 18(5): 668-675, doi: 10.1002/ajhb.20536, indexed in Pubmed: 16917883.

5. Cvetkovic M, Najman S, Nikolic M. Secular changes in cephalic index-a study of Serbian school children. Genetika. 2014; 46(2): 561-568, doi: 10.2298/gensr1402561c.

6. Danilenko GM, Pokroyeva LD, Kratenko IS. Hygienic screening assessment of implementation of health forming innovation in secondary schools. Kharkiv $2006: 76$.

7. Dyachenko VD. Anthroological comosition of the Ukrainian eole. K. Naukova Dumka 1965: 132.

8. Farkas LG, Katic MJ, Forrest CR, et al. International anthropometric study of facial morphology in various ethnic groups/races. J Craniofac Surg. 2005; 16(4): 615-646, indexed in Pubmed: 16077306.

9. Godina EZ, Purundzhan AL, Khomyakov IA. Epochal transformation of the body and head size in Moscow children and adolescents as a criterion for micro-evolutionary processes. The peoples of Russia: from past to present. Part 2: Anthropology. M. Stariy Sad. 2000: 305-330.

10. Hossain MD, Lestrel PE, Ohtsuki F. Secular changes in head dimensions of Japanese adult male students over eight decades. Homo. 2005; 55(3): 239-250, indexed in Pubmed: 15803769.

11. Koh K, Han S, Song W, et al. Secular Changes of Cephalic Index in Korean Adults. Korean J Physical Anthropol. 2001; 14(3): 177-185, doi: 10.11637/kjpa.2001.14.3.177.

12. Kouchi M. Brachycephalization in Japan has ceased. Am J Phys Anthropol. 2000; 112(3): 339-347,doi: 10.1002/1096-8644 (200007)112:3<339::AIDAJPA5>3.0.CO;2-6, indexed in Pubmed: 10861351.

13. Little BB, Buschang PH, Peña Reyes ME, et al. Craniofacial dimensions in children in rural Oaxaca, southern Mexico: secular change, 1968-2000. Am J Phys Anthropol. 2006; 131(1): 127-136, doi: 10.1002/ajpa.20406, indexed in Pubmed: 16485300.

14. Natale V, Rajagopalan A. Worldwide variation in human growth and the World Health Organization growth standards: a systematic review. BMJ Open. 2014; 4(1): e003735, doi: 10.1136/bmjopen-2013-003735, indexed in Pubmed: 24401723.

15. Proffit WR. Modern orthodontics - translated from English. Persina LS, ed. M : MEDpress 2006: 560.

16. Purundzhan AL, Godina EZ, Khomyakov IA, et al. Features of epochal changes in body size and head of children and adolescents of the Republic of Belarus and the Moscow Region. Materials of IV Int. Congreve on Integrative Anthropology. St Petersburg. 2002: 299-301.

17. Purundzhan AL, Khomyakov IA. Processes of epochal transformation of head shape in children and adolescents Russia and Poland. Some problems of modern anthropology. SPb. MAE RAS. ; 2006: 132-137.

18. Shaarenko PP. Anthroometry. Vinnitsa. 2000: 71.

19. Tineshev S, Dimov I. Cephalometric characteristics of children and adolescents from the Eastern Rhodope region - Bulgaria. Glasnik Antropoloskog drustva Srbije. 2013(48): 43-47, doi: 10.5937/gads1348043t.

20. Weber E. Grundriss der biologichen statistic. Aufl Jena. 1961; 4: 13-42.

21. Yusupov RD, Alyamovsky VV, Nikolaev VG, et al. Ethnic peculiarities cephalometry indicators and displays signs of odontology population of Eastern Siberia. In the world of scientific discoveries. Krasnoyarsk. 2013; 7: 139-56.

22. Zellner K, Jaeger U, Kromeyer-Hauschild K. [The phenomenon of debrachycephalization in Jena school children]. Anthropol Anz. 1998; 56(4): 301-312, indexed in Pubmed: 10027042.

23. Zubov AA. Dentistry. Methods of anthroological research. M: Nauka. 2003; 198. 